\title{
Intentionality as the mark of the mental
}

Tim Crane

\section{BRENTANO'S THESIS}

'It is of the very nature of consciousness to be intentional' said Jean-Paul Sartre, 'and a consciousness that ceases to be a consciousness of something would ipso facto cease to exist'. ${ }^{1}$ Sartre here endorses the central doctrine of Husserl's phenomenology, itself inspired by a famous idea of Brentano's: that intentionality, the mind's 'direction upon its objects', is what is distinctive of mental phenomena. Brentano's originality does not lie in pointing out the existence of intentionality, or in inventing the terminology, which derives from scholastic discussions of concepts or intentiones. ${ }^{2}$ Rather, his originality consists in his claim that the concept of intentionality marks out the subject matter of psychology: the mental. His view was that intentionality 'is characteristic exclusively of mental phenomena. No physical phenomenon manifests anything like it'. ${ }^{3}$ This is Brentano's thesis that intentionality is the mark of the mental.

Despite the centrality of the concept of intentionality in contemporary philosophy of mind, and despite the customary homage paid to Brentano as the one who revived the terminology and placed the concept at the centre of philosophy, Brentano's thesis is widely rejected by contemporary

philosophers of mind. What is more, its rejection is not something which is thought to require substantial philosophical argument. Rather, the falsity of the thesis is taken as a starting-point in many contemporary discussions of intentionality, something so obvious that it only needs to be stated to be recognised as true. Consider, for instance, these remarks from the opening pages of Searle's Intentionality:

Some, not all, mental states and events have Intentionality. Beliefs, fears, hopes and desires are Intentional; but there are forms of nervousness, elation and undirected anxiety that are not Intentional.... My beliefs and desires must always be about something. But my nervousness and undirected anxiety need not in that way be about anything. ${ }^{4}$

Searle takes this as obvious, so obvious that it is not in need of further argument or elucidation. And many others agree with him. ${ }^{5}$

${ }^{1}$ The Psychology of the Imagination (London: Routledge, 1995; originally published 1940) 211.

${ }^{2}$ For the origins of the concept of intentionality, see Christian Knudsen, 'Intentions and Impositions' in The Cambridge History of Later Medieval Philosophy A. Kenny et al (eds.) (Cambridge: Cambridge University Press, 1982); Victor Caston, 'Aristotle on the Problem of Intentionality', forthcoming. For a general survey, and further bibliography, see Tim Crane 'Intentionality', forthcoming in the Routledge Encyclopedia of Philosophy, E.J. Craig (ed.) (London: Routledge, 1998).

${ }^{3}$ F. Brentano, Psychology from an Empirical Standpoint (London: Routledge, 1995; originally published 1874) 89 .

4John R. Searle, Intentionality (Cambridge: Cambridge University Press, 1983) 1.

${ }^{5} \mathrm{~A}$ representative example of this position is Colin McGinn, The Character of Mind (Oxford: Oxford University Press, 1982) chapter 1. 
Brentano's thesis is normally rejected for one or both of the following reasons. First, it is supposed to be obvious that there are both intentional and non-intentional mental states: intentionality is not necessary for mentality. Non-intentional mental states can either be of the kind Searle mentions (emotions or moods, like undirected anxiety) or they are the so-called purely 'qualitative' mental phenomena-states which have 'qualia' —of which sensations (like pains) are the most commonly cited examples. Both kinds of example are mentioned in an implicit rejection of Brentano's thesis by Louise Antony:

while mental items like beliefs and desires clearly have objects or contents (an idea is an idea of something, and a desire is a desire for something), things like pleasures, pains, moods and emotions don't, on the face of it, appear to be about anything at all. ${ }^{6}$

Antony remarks in passing that the opposing view-in effect, that pains, moods and emotions are intentional-'seems counter-intuitive'.

The second reason for the rejection of the thesis is that there are nonmental phenomena which exhibit intentionality: intentionality is not sufficient for mentality. Examples are more controversial here, but we find phenomena such as the disposition of plants to move towards the source of light offered as primitive non-mental forms of intentionality. ${ }^{7}$ Not every philosopher who rejects Brentano's thesis rejects it for both of these reasons, but it is nonetheless fair to say that there is a tacit consensus that the thesis should be rejected.

But this consensus raises a puzzling historical and exegetical question. If it is so obvious that Brentano's thesis is false, why did Brentano propose it? If a moment's reflection on one's states of mind refutes the thesis that all mental states are intentional, then why would anyone (including Brentano, Husserl, Sartre and their followers) think otherwise? Did Brentano have a radically different inner life from the inner lives of contemporary philosophers? Or was the originator of phenomenology spectacularly inattentive to phenomenological facts, rather as Freud is supposed to have been a bad analyst? Or-surely more plausibly_-did Brentano mean something different by 'intentionality' than what many contemporary philosophers mean?

The question of what Brentano and his followers meant by 'intentionality' is an important one, both for our understanding of the origin of current debates, and, relatedly, for our conception of these debates themselves. ${ }^{8}$ However, my concern in this paper is not with Brentano's theory of intentionality, but with a more general question: what would you have to believe about intentionality to believe that it is the mark of the mental? I argue here that if we think of intentionality in the light of this

\footnotetext{
${ }^{6}$ Louise Antony, 'What it's Like to Smell a Gardenia' Times Literary Supplement, 4897 (February 7 1997) 25. See also Fred Dretske, Naturalizing the Mind (Cambridge, Mass.: MIT Press, 1995) 28.

${ }^{7}$ For examples of this kind of approach, see Fred Dretske, Knowledge and the Flow of Information (Cambridge, Mass.: MIT Press, 1981); B. Enç, 'Intentional States of Mechanical Devices' Mind 91 (1982).

${ }^{8}$ For a helpful attempt to relate Brentano's concerns to current debates, see Dermot Moran, 'Brentano's Thesis' Proceedings of the Aristotelian Society, Supplementary Volume 70 (1996).
} 
question, a conception of the mental begins to emerge which abandons some of the usual assumptions of contemporary philosophy of mind.

The rest of this paper falls into three parts. In the next two parts I examine the standard counterexamples to Brentano's thesis-certain kinds of sensations and emotions. I argue that they are not genuine counterexamples, and I sketch a conception of intentionality which arises from my the discussion of these examples. In the final part, I claim that intentionality, properly understood, should be thought of as exclusive to the mental domain, and I conclude with some more speculative remarks about the significance of the question; why do we need a mark of the mental at all?

\section{THE INTENTIONALITY OF SENSATION}

Since 'intentionality' is a technical term, it is standard practice when introducing it to use some slightly less technical synonym or gloss. In contemporary philosophy this is often done by saying that intentionality is the about-ness or of-ness of mental states. ${ }^{9}$ Intentional states are those which are about or of things, normally things other than themselves. So one might demarcate the class of intentional states by considering a mental state and asking 'what is it about?'. If the question doesn't make much sense, or if it has the obvious answer 'nothing', then the state is classified as non-intentional. Consider a pain you may have in your ankle; what is it of or about? Silly question: it isn't of or about anything. And so, since intentionality is of-ness or about-ness, pain is not intentional. In this way, we find Colin McGinn arguing that 'bodily sensations do not have an intentional object in the way perceptual experiences do' on the grounds that 'we distinguish between a visual experience and what it is an experience of; but we do not make this distinction in respect of pains.' ${ }^{10}$ This is one quick way to arrive at a denial of Brentano's thesis.

It certainly sounds awkward to talk of a distinction between a pain and what a pain is 'of' or 'about'. But all this means is that those who follow Brentano in holding intentionality to be the mark of the mental-call them 'intentionalists' - will not gloss the concept of intentionality solely in terms of 'of-ness' or 'about-ness'. Intentionalists must introduce what is involved in the phenomenon of intentionality in another way. How should they do this?

Brentano's own view was that every mental phenomenon exhibits what he called 'intentional inexistence'. The term 'inexistence' has little or nothing to do with the fact that intentional states (or 'acts') can be about objects which do not exist. ${ }^{11}$ Rather, the term describes the way in which every intentional act 'includes something as an object within itself' ${ }^{12}$ 'Inexistence' expresses the idea that the object on which the mind is directed exists in the mental act itself. For example: in hearing a sound, the sound

\footnotetext{
9See (for example) Martin Davies, 'Philosophy of Mind' in Philosophy: a Guide Through the Subject A.C. Grayling (ed.) (Oxford: Oxford University Press, 1995); Searle, op. cit. note 4, 1; Fodor, Psychosemantics (Cambridge, Mass.: MIT Press, 1987) Chapter 4.

${ }^{10}$ McGinn, op. cit. note 5, 8 .

${ }^{11}$ For examples of this common misunderstanding of Brentano, see Daniel C. Dennett, Content and Consciousness (London: Routledge and Kegan Paul, 1969) 21; Michael Tye, Ten Problems of Consciousness (Cambridge, Mass.: MIT Press, 1995) 94-95. A useful account of Brentano's views is contained in chapter 1 of David Bell's Husserl (London: Routledge, 1990). For the scholastic views to which Brentano is alluding, see Knudsen, op. cit. note 2, and John Marenbon, Later Medieval Philosophy (1150-1350): An Introduction (London: Routledge 1987) chapter 8.

${ }^{12}$ Brentano, op. cit. note 3, 88 .
} 
which one hears-a physical phenomenon-is contained within the act of hearing the sound-a mental phenomenon. So, to generalise, we can say that 'in the idea something is conceived, in the judgement something is affirmed or denied, in love loved, in hate hated and so on' ${ }^{13}$

Brentano rejected the claim that sensations of pain and pleasure are not intentional. He argued that although intentional acts can take external phenomena as their objects, sometimes their objects are internal. In the case of sensation, for instance, the mind is directed on an internal object-a sensation. ${ }^{14}$ Just as 'in the idea something is conceived', we can say that 'in the sensation something is sensed'. So one response an intentionalist can give to McGinn's argument is this. Intentionality is directedness on an object, and in having a sensation, one's mind is directed on an object: a sensation. A pain, for instance, is the object of the mental state of being in pain. (This way of thinking of sensation is what used to be called an 'act-object' account.)

The idea that sensations are objects is associated with the sense-datum theory of perception, which is not a popular view in contemporary philosophy. These days it is widely agreed that perception does not involve the mind directing itself upon internal, mental objects-sense-data. But this agreement does not derive from a general rejection of the directedness, or intentionality, of perception. On the contrary, there is a widespread consensus-as illustrated by McGinn's remark just quoted-that perception is intentional. It is just that the objects of perception are not inner mental objects or sense-data, but the ordinary outer objects of the external world. So there will be no dispute between intentionalists and many contemporary philosophers over the question of whether perception exhibits intentionality. If perception were the only mental state under discussion, intentionalism would not be a controversial thesis. ${ }^{15}$

There are philosophers, of course, who think that although perception exhibits intentionality-perceptions are directed on things outside the mind-this does not exhaust their nature. This is the view, defended for instance by Sydney Shoemaker, that in addition to their intentional properties, perceptual states also have non-intentional properties, called 'qualia', which account for the particular conscious or 'phenomenal' character of perceptual states. ${ }^{16}$ Qualia are not sensation-objects, but properties of mental states. If there are qualia, then there are aspects or properties of mental states which are not intentional, even if those states also have intentional aspects.

Qualia raise many questions which I want to avoid for the purposes of this paper. Certainly the strongest form of intentionalism will reject qualia

\footnotetext{
$13_{\text {ibid., } 88 .}$

${ }^{14}$ This is the essence of Brentano's response to Sir William Hamilton's view that in sensation 'there is nothing but what is subjectively subjective; there is no object different from the self'; see Brentano, op.cit. note 3, 90.

${ }^{15}$ Here I am taking as 'intentionalist' two kinds of theory of perception: the theory which holds that perception is the direction of the mind upon objects (mental or physical) and the theory which treats perception as a kind of propositional attitude, akin to belief. My usage involves a broader sense of 'intentional' than is sometimes adopted in discussions of the intentionality of perception, where it is restricted to theories of the latter kind: see, for instance, the useful discussion in M.G.F. Martin, 'Perceptual Content' A Companion to the Philosophy of Mind S. Guttenplan (ed.) (Oxford: Blackwell, 1995).

${ }^{16}$ See, for example, Sydney Shoemaker, 'Qualities and Qualia: What's in the Mind?' in his The First-Person Perspective and Other Essays (Cambridge: Cambridge University Press, 1996).
} 
outright, as contemporary intentionalists like Michael Tye and Gilbert Harman have done. ${ }^{17}$ But in this paper, I want to consider only a weaker form of intentionalism, which says that all mental states are intentional, regardless of whether these states also have non-intentional properties. This weaker claim is certainly within the letter of Brentano's thesis that intentionality is the mark of the mental, although it is not so obviously within its spirit. However, there is a good dialectical reason for discussing the weaker thesis first: for if the weaker thesis is false-i.e. there are mental states which are entirely non-intentional-then there is no chance whatsoever of the stronger thesis being true. So from now on, I will mean by 'intentionalism' this weaker thesis.

Let's return now to the first group of apparent counterexamples to intentionalism: bodily sensations like pains, itches and so on. McGinn says that we can distinguish between a visual experience and what it is of, but we do not make this distinction in the case of pains. Pains, on this view, are not about anything, they are not of anything, they represent nothing: they have no intentionality. Rather, pains are purely subjective qualities: their existence consists in the existence of a subjective state that tells us nothing about the external world.

To hold this view is to distinguish pain from other cases of bodily sensation where we are able to distinguish between the sensation and what it is of: sensations of warmth, of cold, of pressure, of tiredness, of hunger can all be described in terms of what they are sensations of, and what they are sensations of are properties of the external world (temperature, pressure etc.). So these are examples of bodily sensations which can be accommodated by intentionalism: the intentionalist can say that these states of mind are intentionally directed at those objective properties of the world in terms of which we characteristically describe them. But what should an intentionalist say about sensations where it does not seem as if this distinction can be made, as seems to be the case with pain?

The answer mentioned above is that there is an object presented in a state of pain, but it is an internal or mental object. Now even if we reject mental objects in the case of the perception of the external world, can a case be made for their existence in the case of bodily sensation?

Phenomenologically, the case for mental objects seems somewhat stronger here than in the theory of visual perception. For it could be argued, against McGinn, that a distinction can be made between a pain and the feeling of the pain. Consider, for example, someone being woken up from a dreamless sleep by a pain. For the pain to have woken the person up, and therefore to have caused the person to wake up, it must have existed prior to the awakening. But since the awakening is a matter of becoming conscious of various things, including the pain, it might seem that the pain can exist without the consciousness of it. Less controversially, perhaps, we can distinguish between having a pain and noticing or paying attention to a pain; we might therefore think that we can 'pull apart' the pain itself and our attitude to or awareness of it. These phenomena seem to provide some support for the view that pains are distinct from the consciousness or awareness of pain, and that we can therefore think of pains as the entities on

\footnotetext{
${ }^{17}$ See Gilbert Harman, 'The Intrinsic Character of Experience' Philosophical Perspectives 4: Action Theory and Philosophy of Mind, J. Tomberlin (ed.) (Ascadero, CA: Ridgeview, 1990); and Michael Tye, 'Visual Qualia and Visual Content', The Contents of Experience, Tim Crane (ed.) (Cambridge: Cambridge University Press, 1992).
} 
which the mind is directed in states of pain. Further features of the way we think and talk about sensations lend some plausibility to the view. Pains normally seem to have location and extension in space and time, and we effortlessly talk about them using singular terms and we predicate properties of them as we do of objects and events. ${ }^{18}$

While many contemporary philosophers are happy to accept the existence of irreducible mental properties, it is fair to say that most would prefer to reject irreducible mental objects. ${ }^{19}$ Mental objects are generally rejected for metaphysical reasons: their criteria of identity are obscure, and it is hard to see how they can be accomodated by a 'naturalistic' world view. However, my concern in this paper is with not with metaphysics, but with phenomenology: the correct account of how things seem to us. It would be consistent to hold that although phenomenology commits us to mental objects, nonetheless we know on metaphysical grounds that there are no such things. To say this would be to hold an 'error-theory' of the phemonology of sensation, analogous to J.L. Mackie's error theory of the phenomenology of ethical value. ${ }^{20}$

Although I think that we must be alive to this possibility, it seems to me that-independently of the metaphysical objections to mental objects-phenomenology does not decisively establish their apparent existence. For each of the examples discussed above admit of alternative, equally plausible descriptions which do not require us to posit mental objects. The phenomenon of being woken by pain, for instance, can be redescribed as follows: I might be in pain when I wake up, but it does not follow from this that the pain woke me up. It is equally consistent with the story that I was awoken by some non-conscious event in my brain, which then gave rise to pain when I become conscious. Likewise, the attempt to separate pain from the consciousness of pain by appealing to the distinction between having a pain and attending to it ignores the complexity of the phenomenology of attention and awareness. There are different ways of being aware of an event in consciousness: even when I am not paying attention to it, a pain can nonetheless be in the background of my consciousness. ${ }^{21}$

But I do not need to dwell on the arguments for mental objects here, since the defence of intentionalism does not need to appeal to them. Intentionalism about bodily sensations can be defended instead by appealing

\footnotetext{
${ }^{18}$ Those who approach questions of ontology via questions of logical form might say that just as we can argue for the existence of propositions, the objects of belief, by analysing the logical form of valid inferences involving belief-sentences, so we can argue for the existence of pains, the objects of pain-states, by looking at the valid inferences which are made with statements concerning pain. For example: $X$ has a pain in his foot; therefore there is something $\mathrm{X}$ has in his foot. The plausibility of these arguments is, in my view, relatively superficial, for the reasons given in note 21 below.

${ }^{19}$ A notable exception is Frank Jackson, Perception (Cambridge: Cambridge University Press, 1977). However, Jackson no longer holds these views.

${ }^{20}$ See J.L. Mackie, Ethics (Harmondsworth: Penguin Books, 1977), chapter 1.

${ }^{21}$ As Michael Martin says: 'at best [these cases] demonstrate the gap between having a feeling and making a judgement about it'. See M.G.F. Martin, 'Bodily Sensations' forthcoming in the Encylopedia of Philosophy E.J. Craig (ed.) (London: Routledge, 1988). Nor are the inferences involving statements about sensations uncontroversial; for although we might be happy with the inference from ' $X$ has a pain in his foot' to 'There is something which $X$ has in his foot', the inference from ' $X$ has a pain; $Y$ has a pain; therefore there is something which $X$ and $Y$ both have' is clearly invalid if the 'something' is supposed to be a particular object, and irrelevant to the present issue if it is supposed to be a property.
} 
to a perceptual account of bodily sensations, such as that of D.M. Armstrong, or the kind more recently defended by Michael Martin. ${ }^{22}$ On this account, bodily sensation is a form of perceptual awareness of one's body. It is by experiencing bodily sensations that we come to be aware of the state of our body, and of events happening within it. The qualities of which we are aware of in bodily sensation-the sensory qualities of hurting, feeling cold or warm and so on-are predicated in these experiences of parts of the body. When one feels a pain, one normally feels it to be in a part of one's body; and even when a pain is felt where there is no body-part in which to feel it-as in the case of phantom limb pains-what subjects feel is that their body extends further than it actually does. They do not feel as if their pain exists in mid-air, a few inches from where they have lost their limb.

The strongest considerations in favour of this view derive from this felt location of bodily sensation. An ache in my hand feels to be in my hand, not in my mind. Rather than being something which is contained within my mind, it presents itself as something on which my mind can concentrate, attend to, and try to ignore. In fact, this much is common ground between the believer in mental objects and the perceptual theory. But what tells in favour of the perceptual theory is the fact that to concentrate on the ache, I must necessarily concentrate on the part of my body which aches; the mental object theory cannot explain this necessity. Attending to bodily sensations is achieved by attending to a part of the body where these sensations feel to be. This is because bodily sensation is a form of awareness, the awareness of things going on in one's body. ${ }^{23}$

Why call this intentionality? What this perceptual theory says is that in bodily sensation, something is given to the mind, namely the body, or a body part. Calling this phenomenon 'intentionality' classifies it together with the case of outer perception, where the perceived portion of the world is 'given' to the mind; and with thought, where some object, property or state of affairs is 'given' to the mind. What is in common between these different states of mind is expressed in Brentano's formulation: 'in the idea something is conceived, in the wish something is wished'. And in the sensation something is sensed: the body.

\section{THE INTENTIONALITY OF EMOTION}

That is the basis of my case for an intentionalist view of bodily sensation. I now want to move on to the second kind of counterexample to Brentano's thesis: Searle's examples of 'nervousness, elation and undirected anxiety'. How should an intentionalist deal with these apparent examples of nonintentional mental phenomena?

\footnotetext{
22See D.M. Armstrong, A Materialist Theory of the Mind (London: Routledge and Kegan Paul, 1968); M.G.F. Martin, 'Bodily Awareness: a Sense of Ownership' The Body and the Self, J-L. Bermúdez, N. Eilan and A. Marcel (eds.) (Cambridge Mass.: MIT Press, 1995); and his 'Sense Modalities and Spatial Properties' Spatial Representation, B. Brewer, N. Eilan and R. McCarthy (eds.) (Oxford: Blackwell, 1993).

${ }^{23}$ Note that an advantage of this view is that it can give a univocal account of both the bodily sensations which are naturally identified in terms of what they are of-warmth, cold, pressure etc. - and those which are not, like pains and so on. This version of the thesis that bodily sensations are intentional should be contrasted with Tye's view that pains give one non-conceptual representations of damage to one's body: see Tye, op. cit., note 11, chapter 4. Tye's view is, however, consistent with the view defended here. Pains may have many levels of representational content; my concern in this paper is with the uncontroversial phenomenological content they appear to have.
} 
First we need to identify the phenomena in question. This is actually harder to do than it might initially seem. Everyone will agree that there is such a thing as being anxious and yet not being able to give an answer to the question 'what are you anxious about?'. But this by itself does not show that anxiety can lack intentionality. For one thing, we have just seen that asking 'what is X about?' is not always the most uncontroversial way of deciding whether $\mathrm{X}$ is intentional. And more importantly, it should not be a condition of a state's being intentional that the subject of that state must be able to express what the state's content is, or even which kind of state it is. Every theory of intentionality must allow that subjects are not always the best authorities on all the contents of their minds.

A possible intentionalist account of the state of mind in question would be to say that the intentional object of the state of mind is its cause. So on this view, when we describe ourselves as 'just anxious without being anxious about anything in particular', we mean that we do not know the cause of our anxiety. Now in some cases, it is certainly true that to identify the cause of an emotion is to identify its intentional object. But this cannot be true in general. For one thing, the object of the emotion might lie in the future. Or the cause of an emotion might be a past event which is too remote from the present manifestation of the emotion to be properly regarded as its object. (It may be true that the cause of someone's fear of dogs was a childhood encounter with a certain dog-but it would not always be right to say that that dog was the object of their current state of fear in the presence of a different dog.) Or the cause of the emotion might be something completely unrelated to its object. (A drug may cause you to hate some person or thing.) So the fact that an emotion has a cause does not by itself entail that it has an intentional object. The intentionalist cannot refute Searle merely by pointing to the fact that emotions have causes of which we are sometimes ignorant.

But, as we have just seen, nor can Searle infer that there are nonintentional emotions merely from the fact that we sometimes say we are anxious without being able to say what we are anxious about. Searle presents the existence of non-intentional emotions as of it were something entirely obvious. An intentionalist, however, will deny that it is obvious. There can be no real debate about this matter if we are restricted to each participant stating what they think is obvious. So how can the debate proceed?

In order to assess the what is at issue between Searle and the intentionalist, we need to know more about how they would classify the various emotions into kinds. What is it that makes anxiety, for instance, the state it is? Whatever it is, it must be common to the cases where anxiety clearly does have an intentional object and the cases which Searle is calling 'undirected'. Remember that these are the cases where someone is anxious but it is not clear to them what they are anxious about. The issue between Searle and the intentionalist is whether the existence of these cases establishes that there are mental states which have no intentionality. If we learn more about what the intentionalist and non-intentionalist think emotions are, we can assess their competing claims over whether any of them are 'undirected' in Searle's sense.

Let's start with non-intentionalism, Searle's position. Perhaps nonintentionalism could say that anxiety is distinguished from (say) an undirected state of contentment by the functional roles of the two states. The functional roles must be explicable in commonsense psychological vocabulary, since we are after a phenomenological classification of the emotions. And yet the functional roles must be relatively 
informative-'behaving anxiously' will not do, in this context, as a characterisation of the functional role of anxiety. So perhaps we can say that anxiety is characterised by the anxious person's inability to concentrate, or by an obsessive concern with trivial details of life, or by jumpy, nervous form of behaviour. Contentment, by contrast, might be characterised by a benign way of behaving towards the world, an enthusiasm for its daily tasks and so on. However, this style of identifying the functional roles of anxiety and contentment does so in terms of forms of behaviour which are manifestly intentional. So while it might suffice for an account of intentional ('directed') anxiety, it will not do for undirected anxiety.

For the non-intentionalist, there must be something directed and undirected anxiety have in common, which licenses them both being called 'anxiety'. And this 'something' must be detectable from the subject's point of view, if Searle's claim is going to have any force-remember that Searle was appealing to what is obvious to us. Yet this something must also be nonintentional: it cannot be directed on anything. So the non-intentionalist must say that an emotion like anxiety (directed or undirected) has properties which are phenomenologically detectable to the subject, but are non-intentional, involving nothing beyond themselves. These properties must therefore be qualia: non-intentional, subjective properties. Just as there are (according to many philosophers) pain-qualia and seeing-red-qualia, there are also emotion-qualia which give the emotions the characteristic phenomenal 'feel' which they have.

Let us suppose, then, that anxiety is partly characterised by its distinctive qualia. Now it is a plausible general thesis about qualia that there is no intrinsic connection between any particular quale and being in any particular objectively-identifiable mental state. For instance, there is nothing intrinsic to the qualia involved in seeing red that links these qualia with the state which plays the functional role of seeing red in normal observers. The coherence of inverted qualia thought-experiments depends on there being no such links, and most defenders of qualia, like Shoemaker, believe that qualia inversion is possible. ${ }^{24}$ In fact, it seems part of the very idea of qualia that there be this possibility: for qualia 'point to' nothing beyond themselves, which would make them associated with one kind of objectively-identifiable state rather than another.

So on the non-intentionalist view of emotion, it must be true that there is nothing about the qualia associated with anxiety themselves which make them anxiety-qualia: that is, associated with a state with the particular functional role of anxiety. Just as seeing-red-qualia could, in some other possible world, be associated with the state which in the actual world is seeing green, so anxiety-qualia could be associated with some other emotion-state, say contentment. This is because there is nothing in the qualia themselves which connects them with particular kinds of emotion, objectively identified (for instance, in terms of functional role).

So now it appears that a non-intentionalist has to accept the possibility that there is a world in which contentment feels to someone as anxiety feels to me. And while the inverted qualia story seems plausible when applied to simple colour-qualia - after all, why shouldn't green things look to you the way red things do to me? - the story is very hard to believe when applied to the putative emotion-qualia. For here we are supposing that the same

\footnotetext{
${ }^{24}$ See Shoemaker op. cit. note 16, 108-113, where he discusses the inverted qualia speculation.
} 
emotion might feel in opposite ways to two subjects in different possible worlds-emotions have their distinctive 'feel' only contingently. But does this possibility really make sense?

One might respond to this: so much for the plausibility of the view that there are emotion-qualia. And I agree: even if there are qualia, to assimilate anxiety to the experience of seeing red is a distortion of ordinary experience. But how else is the non-intentionalist going to describe the characteristic phenomenology of anxiety, undirected and directed? The nature of these states cannot be described in terms of how things seem to the subject, however vaguely stated. For descriptions of how things seem are patently intentional, and so they will not capture the phenomenology of undirected anxiety. Non-intentionalism is committed to emotion-qualia because it is committed to emotions having properties which are non-intentional yet phenomenologically salient-and non-intentional, phenomenologically salient properties of mental states just are qualia, by definition.

But what is the alternative to this non-intentionalist view? How should an intentionalist give an answer to the question about how to distinguish the different emotions? One answer has already been suggested. Someone experiencing anxiety might not be able to put into words what it is they are anxious about; but they may still be able say how things seem to them in their state of anxiety. And even if they can't express it, there is still nonetheless such a thing as how things seem to them. To begin with, the intentionalist will start by distinguishing being anxious for oneself, and being anxious for another. This is clearly an intentional distinction: in the one case, one's mind is directed on oneself, in the other case, it is directed on another. The cases Searle mentions are are not cases where one is anxious for another: otherwise it would be directed anxiety. So the intentionalist will say that these are cases where one is anxious for oneself-so in these cases, one's anxiety is directed upon oneself. Being anxious in this way is a matter of having a certain attitude to oneself and one's position in the world: it is to regard the world, for example, as a potentially disturbing place for oneself. This is one way in which anxiety exhibits directedness. And it is an alternative to seeing Searle's cases as examples of mental states which are directed on nothing, as Searle does.

It might be helpful to contrast, in these very general terms, anxiety with depression. In depression, the world seems to the subject to be a pointless, colourless place: nothing seems worth doing. The change involved in coming out of a depression is partly a change in the subject's apprehension of the world. Things seem to have a significance, a purpose which they previously lacked. And this can be true of a subject even when they cannot say what they are depressed about. In this way, the phenomenon Searle would call 'undirected depression' can be seen as having a certain directedness or intentionality.

These brief remarks suggest that the difference between anxiety and depression resides in the different manners in which the world, and the subject's place in the world, are apprehended in the emotion. This was Sartre's view:

My melancholy is a method of supressing the obligation to look for .. new ways [to realise the potentialities of the world] by transforming the present structure of the world, replacing it with a totally undifferentiated structure... In other words, lacking both the ability and the will to carry out the projects I formerly entertained, I behave 
in such a manner that the universe requires nothing more from me. This one can only do by acting upon oneself, by 'lowering the flame of life to a pin-point' - and the noetic correlate of this attitude is what we call Bleakness: the universe is bleak; that is, of undifferentiated structure. ${ }^{25}$

Sartre's view of emotions, in general, is that they are characterised by their intentionality. 'Emotion is a specific manner of apprehending the world'26 he writes, and 'all the emotions have this in common, that they evoke the appearance of a world, cruel, terrible, bleak, joyful etc.'. ${ }^{27}$ Sartre's view provides one general framework in which to defend the intentionality of all emotions - even those which Searle describes as 'undirected'.

Let me summarise this line of thought. Searle says that there are emotions which have no intentionality. But this does not follow from the fact that people cannot say what it is that their emotions are about. Nor does its denial follow from the fact that the objects of emotions are sometimes their causes, of which we are sometimes ignorant. To decide the issue about whether there are non-intentional emotions, we should first ask what disinguishes, from the phenomenological point of view, the different emotions. The non-intentionalist answer to this question is committed to the existence of emotion-qualia, and the implausible possibility of inverted emotion-qualia. But the intentionalist who accepts (for example) Sartre's view of emotion as a mode of apprehending the world is not committed to this possibility. The differences between the different emotions would not be explained in terms of qualia but in terms of the different ways the emotions present the world and the subject's place in it. This is one way an intentionalist can characterise the emotions Searle is talking about, like anxiety and depression, where the subject is not able to say what they are anxious or depressed about.

The phenomenology of emotion is a very complex area, and I have only touched the surface of the issues. What I have tried to do is to suggest a way in which an intentionalist can argue that these apparent counterexamples to Brentano's thesis are not really counterexamples. ${ }^{28}$ But what does this treatment of the counterexamples show about the nature of intentionality in general?

My original question was: what would you have to believe about intentionality in order to believe that it is the mark of the mental? The way I have approached this question is to try and specify the sense in which something is 'given' to the mind in sensation and emotion, just as something is given to the mind in thought and experience. The heart of the view is inspired by Brentano's phrase that in the idea, something is conceived; I say that in the sensation, something is felt, in the emotion, something is apprehended-and so on.

The issue is in danger of collapsing into an uninteresting question of terminology if the notion I am identifying as intentionality had nothing in

\footnotetext{
${ }^{25}$ Sketch for a Theory of the Emotions (London: Methuen 1971; originally published 1939) 68-69. For an illuminating introduction, see Gregory McCulloch, Using Sartre (London: Routledge, 1994) chapter 2.

${ }^{26}$ Sartre, op. cit. note 25,57 .

27 ibid., 81.

${ }^{28}$ Of course, this is not the only way for an intentionalist to account for emotion. Compare Tye's views: Tye, op. cit., note 11, chapter 4 .
} 
common with what others call intentionality. But this is not the case. It is possible to isolate two main elements of the concept of intentionality as discussed by recent philosophers. ${ }^{29}$ The first is the apparently relational structure of intentionality, the structure Sartre and other phenomenologists express by saying that consciousness is always the consciousness of something. ${ }^{30}$ While intentional states appear to be relations between thinkers and the objects of their thoughts, this cannot be true in general, since intentional states can be directed on things which do not exist, and relations entail the existence of their relata. ${ }^{31}$ (This point holds independently of the truth or falsity of the doctrine of externalism, since even the most extreme externalist must allow that intentional states can concern the non-existent.) The second element is what some call the perspectival or fine-grained nature of intentionality, what Searle calls 'aspectual shape'. ${ }^{32}$ This is just the familiar idea that when something is apprehended as the object of an intentional state-whether a particular object, fact or property-it is always apprehended in a certain way.

Both features of intentionality are present in my treatment of the counterexamples to intentionalism. I claimed that instead of seeing bodily sensations as instantiations of purely subjective, monadic properties, we should see these experiences as presenting something - a part of the body-as modified in a certain way. Bodily sensations, then, are primarily states of awareness, and therefore apparently relational states. They are only apparently relational since, according to the perceptual theory, phantom limb

\footnotetext{
${ }^{29}$ For a representative of recent discussions, see Tye, op. cit., note 11, 94-96.

${ }^{30}$ For instance: 'all consciousness, as Husserl has shown, is consciousness of something' Being and Nothingness (London: Methuen, 1958; first published 1943) xxvii. Compare Searle: 'It is characteristic of Intentional states, as I use the notion, that there is a distinction between the state and what the state is directed at or about or of.' op. cit. note 4, 2; for a different way of formulating the same kind of point, see E. Levinas, 'Beyond Intentionality' Philosophy in France Today A. Montefiore (ed.) (Cambridge: Cambridge University Press, 1983) 106.

${ }^{31}$ This fact gives rise to one of the main problems of intentionality. For an excellent presentation of this problem, see Michael Dummett, Origins of Analytical Philosophy (London: Duckworth, 1993) 35-36. See also Caston, op. cit., note 2. Brentano came to appreciate the importance of this point when he wrote the appendix to his Psychology from an Empirical Standpoint (op. cit. note 3). There he says that 'If someone thinks of something, the one who is thinking must certainly exist, but the object of his thinking need not exist at all'. He goes on to observe that 'we might doubt whether we are dealing with something relational here, and not, rather, with something somewhat similar to something relational in a certain respect, which might therefore better be called "quasi-relational"' (Brentano, op. cit., 272). Sometimes it is supposed (see Dennett op. cit. and Tye op. cit. note 11) that Brentano was concerned with the question of non-existence even before he wrote the Appendix to his Psychology. It is true that in a famous passage, Brentano says that the object of thought 'should not be understood as a reality' (88); but by this he is just reminding his readers that he is talking about 'phenomena' or 'appearances', not about the 'underlying reality'. In this sense, the physical phenomena with which he contrasts mental phenomena 'should not be considered a reality' either. Compare, for example, the following passage: 'the phenomena of light, sound, heat, spatial location and locomotion which [the natural scientist] studies are not things which really and truly exist. They are signs of something real, which through its causal activity, produces presentations of them. They are not however, an adequate representation of this reality... We have no experience of that which truly exists, in and of itself, and that which we do experience is not true.' Brentano, op. cit. note 3, 19.

32John R. Searle, The Rediscovery of the Mind (Cambridge, Mass.: MIT Press, 1992) 155.
} 
phenomena (e.g.) are cases of awareness of a felt quality in merely apparent body part. They are therefore analogous - in this respect only-to cases of perceptual hallucination, where one perceives a quality to be instantiated in an object which does not actually exist. ${ }^{33}$ If Sartre's account of the phenomenology of emotions is right, then there is a similar apparent relationality in emotional experience: there is the experiencing subject, the world experienced (or the thing in the world experienced) and the particular way of apprehending the world.

The second element of intentionality-its fine-grained character-is also contained within my account of sensations and emotions. A pain in one's ankle is a state of awareness of one's ankle, presented as such, not as the organic organisation of tendons, bone and muscle which one's ankle actually is. Similarly with the so-called 'undirected' emotions. In a particular undirected emotion, the same world appears under one aspect-bleak, terrible, threatening-rather than another. (Of course, there may be debate about whether the world could properly be said to have the aspects or properties attributed to it in an emotion-but this does not affect the present point.)

So the core of the concept of intentionality, as discussed in much contemporary philosophy of mind, is present in the theses advanced by intentionalism. The dispute between the intentionalist and the nonintentionalist is substantial and not just terminological. Where this characterisation does depart from some recent discussions is in not starting the discussion of intentionality with the notion of a propositional attitude. A propositional attitude is an intentional state whose content-that which characterises its directedness - is something evaluable as true or false. I do not question the applicability of the notion of a propositional attitude itself, but rather the tendency in some contemporary philosophers to see the propositional attitudes as the sole home of the concept of intentionality. ${ }^{34}$ Obviously, the form of intentionalism I am defending here cannot accept such a view, but even putting this to one side, the thesis that all intentional mental states are propositional attitudes lacks phenomenological plausibility. To take a nice example of Victor Caston's: when asked to think of a number between one and ten, what comes to mind is a number, not a proposition. And it is a familiar fact that certain emotions, notably love and hate, can be directed on objects rather than always on states of affairs. While the notion of a propositional attitude must play an important role in any theory of intentionality, it does not exhaust the application of the concept of intentionality.

\footnotetext{
${ }^{33}$ Only in this respect, since it is not quite correct to say that a phantom limb pain is an illusory pain - the pain certainly exists, one just perceives it as having a location which it does not (indeed, in the circumstances, cannot) have. An analogy would be perhaps with some device which made it seem to you as if sounds were coming from one direction when they were in fact coming from the opposite direction (as when a ventriloquist 'throws' his voice).

${ }^{34}$ For a clear-headed (but in my view mistaken) statement of this policy, see Dennett, op. cit. note 11, 27-29. Even Searle (op. cit, note 4) who admits that much intentionality cannot be expressed in terms of whole propositions (6-7), seems to commit himself implicitly to the opposite in his analysis of intentional states by analogy with his account of speech acts (26).The tendency is still pervasive: see, for instance, the definition of 'intentionality' given in William Lyons, Approaches to Intentionality (Oxford: Oxford University Press, 1995) 1-2.
} 


\section{INTENTIONALITY, THE NON-MENTAL AND THE MARK OF THE MENTAL}

I have been defending the claim that all mental phenomena exhibit intentionality. Now I want to return to the other part of Brentano's thesis, the claim that intentionality is exclusive to the mental domain. This will give me the opportunity to air some speculations about why we should be interested in the idea of a mark of the mental.

Now, the way I am suggesting we should think about intentionality, it is a concept which applies to all mental phenomena, including conscious, phenomenally salient mental states such as perception, sensation and conscious emotional episodes, but also to unconscious beliefs, desires and other mental dispositions. The binding idea is captured by the Brentanian slogan that in the intentional state something is given. But can we find intentionality in the non-mental?

It is sometimes said that Brentano's thesis is a threat to physicalism because it implies that intentionality can only be found in the mental and never in the physical. Dennett, for instance, says that 'the Intentionalist thesis ... proclaims an unbridgeable gulf between the mental and the physical' ${ }^{35}$

But we must distinguish between the view that intentionality is not present in the physical, and the view that intentionality is not present in the non-mental. For if physicalism is true, then the physical is not the same as the non-mental. Of course, Brentano himself-to whom the question of physicalism would have been of little interest-says that 'no physical phenomenon manifests anything like' intentionality. But if we want to remain neutral on the question of physicalism, we should prefer a weaker version of Brentano's thesis which only says that intentionality is characteristic of the mental alone. Whether the mental is reducible to the physical is a further question; if it is, then some physical things manifest intentionality. But no non-mental things do.

However, some philosophers take a view of intentionality which makes it unproblematically a feature of many non-mental things. For instance, some follow Chisholm and Quine and take the non-extensionality of certain linguistic contexts as criterial for the intentionality of the phenomena described in those contexts. ${ }^{36}$ Chisholm's approach was to 'formulate a working criterion by means of which we can distinguish sentences that are Intentional ... in a certain language from sentences that are not' ${ }^{\prime}{ }^{37}$ In essence Chisholm's criterion was that a sentence $S$ is intentional iff: $S$ contains a singular term yet does not entail the usual existential generalistion; or $S$

\footnotetext{
${ }^{35}$ Dennett, op. cit. note 11, 21. The point derives from Quine: see Word and Object (Cambridge Mass.: MIT Press, 1960), 221. See also the opening pages of Hartry Field, 'Mental Representation' Readings in the Philosophy of Psychology vol. II, Ned Block (ed.) (London: Methuen, 1980). Obviously, if one thinks of intentionality as a property of sentences (as Quine and Dennett do) Dennett's quoted remark makes more sense than it would do otherwise. I quote it here because the idea that Brentano's thesis presents a problem for physicalism has survived the waning of the popularity of the linguistic criterion of intentionality.

${ }^{36}$ See Chisholm, Perceiving (Ithaca: Cornell University Press, 1957), chapter 12, and Quine, op. cit. note 35, esp. the $\S$ on 'The Double Standard'. Note especially the following passage: 'the Scholastic word 'intentional' was revived by Brentano in connection with the verbs of propositional attitude and related verbs ... e.g. 'hunt', 'want' etc. The division between such idioms and the normally tractable ones is notable. We saw how it divides referential from non-referential occurrences of terms.'

${ }^{37}$ Chisholm, op. cit. note 36, 170.
} 
contains an embedded sentence in a non-truth-functional context; or the principle of the substitutivity of co-referring singular terms does not apply to $S$. This disjunctive criterion is supposed to establish the intentionality (in Brentano's sense) of the phenomena described by the sentence S. Dennett, for instance, says that 'Chisholm's three criteria come close to reproducing Brentano's distinction'. ${ }^{38}$

I will call this this the 'linguistic criterion' of intentionality. Some of those who adopt the linguistic criterion take a deflationary approach to the distinctively mental characteristics of intentionality. They point out that intentionality, in their sense, is common to non-mental linguistic contexts, too-for instance: modal, causal, dispositional, probabilistic or functional contexts-and they draw various conclusions from this fact. They might draw the relatively weak conclusion that intentionality is not the mark of the mental; or they might draw the stronger conclusion that there is no special problem of intentionality, if intentionality is shared by so many different and (in some cases) unproblematic phenomena. ${ }^{39}$

The version of intentionalism defended here cannot accept this. This is not to say that it would have to reject the view that causal, probabilistic and the other contexts are non-extensional. Nor does intentionalism have to deny that the features of intentionality I have just mentioned receive expression in the linguistic structures which we use to describe it. So, for instance, the apparent relationality is evident in ascriptions of intentionality (in the failure of existential generalisation in non-extensional contexts) as is the fact that intentionality is perspectival (in the failure of substitutivity of co-referring terms).

What intentionalism must reject is rather the linguistic criterion of intentionality itself. These linguistic phenomena are guides to the presence of intentionality in ascriptions of intentionality, but they do not constitute its essence. And given the way I have been proceeding in this paper, this should not be suprising. Intentionality, like consciousness, is one of the concepts which we use in an elucidation of what it is to have a mind. On this conception of intentionality, to consider the question of whether intentionality is present in some creature is of a piece with considering what it is like for that creature - that is, with a consideration of that creature's mental life as a whole. To say this is not to reject by stipulation the idea that there are primitive forms of intentionality which are only remotely connected with conscious mental life-say, the intentionality of the information-processing which goes on in our brains. It is rather to emphasise the priority of intentionality as a phenomenological notion. ${ }^{40}$ So intentionalists will reject the

\footnotetext{
${ }^{38}$ Dennett, op. cit. note 11, 23. Compare Searle, op. cit., note 4, 22-25, who takes the correct view of this matter, as I see it. See also William Kneale, 'Intentionality and Intensionality' Proceedings of the Aristotelian Society Supplementary Volume 42 (1968). ${ }^{39} \mathrm{~A}$ good example of this general approach is Enç, op. cit. note 7; see also C.B. Martin and Karl Pfeifer, 'Intentionality and the Non-Psychological' Philosophy and Phenomenological Research 46 (1986), and U.T. Place 'Intentionality as the Mark of the Dispositional' Dialectica 50 (1996).

${ }^{40}$ For the idea of intentionality as a phenomenological notion, see Gregory McCulloch, 'The Very Idea of the Phenomenological' Proceedings of the Aristotelian Society 93 (1992-93); and 'Intentionality and Interpretation', this volume; J.E. Malpas, in Donald Davidson and the Mirror of Meaning (Cambridge: Cambridge University Press, 1992), §4.2, gives an interesting reading of intentionality as a phenomenological notion, drawing on the Heideggerian notion of a 'horizon'. For a survey of various ways in which the idea of intentionality can be applied beyond the central cases, see Martin Davies, 'Consciousness
} 
linguistic criterion of intentionality precisely because the criterion will count phenomena as intentional which are clearly not mental.

This would be a perverse or circular way to proceed if we did not already have a grasp on the concept of a mind. But we do have such a grasp: it is that concept which we try and express when we say that to have a mind is to have a point of view or perspective on the world, or when we say that there is something it is like to be conscious, or when we talk about the world being manifest to a subject of experience, or when we talk about the world being a phenomenon for a subject. Some philosophers associate these ways of talking solely with the conscious or phenomenal side of the mind, where the conscious or the phenomenal is contrasted explicitly with the intentional. ${ }^{41}$ Consider, for instance, how McGinn formulates his pessimism about our inability to explain consciousness:

We can, it is felt, explain what makes a mental state have the content it has; at least there is no huge barrier of principle in the way of our doing so. But, it is commonly conceded, we have no remotely plausible account of what makes a mental state have the phenomenological character it has. ${ }^{42}$

Here 'phenomenological character' is explicitly contrasted with 'content', as if the two categories were exclusive. Sometimes composite states are envisaged-as when perceptions are conceived of as having content and qualia. But in general, the picture of the mind which lies behind remarks such as McGinn's is one on which we have two kinds of mental state: intentional states which are not essentially conscious, and conscious states whose consciousness is intrinsically unrelated to any intentionality they may have.

The trouble with this picture of the mind is that the classification of both kinds of phenomena as mental seems to lack a rationale. The most we can say is that mental is an accidental category, which presupposes no underlying nature to the phenomena it picks out. As Kathleen Wilkes puts it, 'it is improbable that something bunching together pains, and thoughts about mathematics, is going to be a reliable pointer towards a legitimate natural kind'. ${ }^{43}$ Wilkes here echoes Richard Rorty's complaint of about the heterogeneity of the concept of mind:

The attempt to hitch pains and beliefs together seems ad hoc-they don't seem to have anything in common except our refusal to call them 'physical' ${ }^{44}$

There are two possible ways of reacting to these points. One is simply to accept that there is no more than a nominal unity to the concept of mind. The other is to object that there is something wrong with the whole

and the Varieties of Aboutness' Philosophy of Psychology: Debates on Psychological Explanation Cynthia and Graham Macdonald (eds.) (Oxford: Blackwell 1995).

${ }^{41}$ For the contrast between the phenomenal and the intentional, see, for example, Sydney Shoemaker, The First-Person Perspective and Other Essays (Cambridge: Cambridge University Press, 1996) 112, 138.

${ }^{42}$ Colin McGinn, 'Consciousness and Content' The Problem of Consciousness and Other Essays (Oxford: Blackwell, 1991) 24. See also his later remark that 'subjective features lie quite outside the proper domain of the theory of content' (33).

${ }^{43}$ Quoted by Martin Davies, op. cit., note 40, 358.

${ }^{44}$ Richard Rorty, Philosophy and the Mirror of Nature (Oxford: Blackwell, 1979) 22. 
picture-specifically, with the way of distinguishing between intentionality and consciousness that we find expressed, for instance, in the above passage from McGinn. If this is our reaction, then we need to find a way of characterising mental phenomena which reflects the underlying unity of their classification as mental: that is, we need a mark of the mental.

Some philosophers have argued recently that consciousness is the only true mark of the mental..$^{45}$ But this view battles with the widely accepted and uncontroversial view that many mental states are unconscious, so its defence is an uphill struggle. The alternative, which I have been canvassing here, is that it is intentionality, the mind's directedness on the world, which should be thought of as the mark of the mental. If we take this view, then we must reject the distinction implicit in McGinn's, Rorty's and Wilkes's remarks, that the phenomenal is one thing, the intentional another. Whatever the fate of qualia, we must accept that all mental states are permeated with intentionality, and characterising their phenomenal character-giving a phenomenology — can be achieved by characterising their intentionality. 46 Brentano's view was that the science of psychology should be distinguished from both physiology and philosophy, not by its methods, but by its subject-matter. These days, it is less common for there to be serious dispute among psychologists about the subject-matter of psychology. But there is perhaps more disagreement in today's philosophy of mind about what its subject-matter is, and in some cases there is even disagreement about whether it has one. Those who find this situation unacceptable may wish to reconsider the popular rejection of Brentano's thesis that intentionality is the mark of the mental, and therefore the subject-matter of the philosophy of mind. ${ }^{47}$

Department of Philosophy University College London Gower Street London WC1E 6BT

\footnotetext{
${ }^{45}$ See John Searle, op. cit., note 32; for his view of the unconscious, see 155-156. A similar view is taken by Galen Strawson in Mental Reality (Cambridge, Mass.: MIT Press, 1995): 'the only distinctively mental phenomena are the phenomena of conscious experience' (xi). ${ }^{46}$ For some different approaches to the same idea, compare M.G.F. Martin, 'Setting Things Before the Mind' this volume; and Gregory McCulloch, 'Intentionality and Interpretation', this volume. My remarks in this last section are highly speculative, and raise many issues which demand further elaboration. One question is whether the suggested 'unification' of the phenomena of mind by the concept of intentionality can be achieved within the weak intentionalist picture I defend here. For if one allows that the existence of non-intentional phenomenal properties (qualia) is compatible with the intentionality of all mental states, then it appears as if a question can be raised for weak intentionalism which is parallel to the question I am raising for the McGinn/ Rorty picture. More needs to be said about nonintentional properties in order to assess the force of this question. Here I am indebted to participants in the discussion at the Royal Institute of Philosophy meeting, and especially to Paul Boghossian.

${ }^{47}$ I am very grateful to Michael Martin and Gregory McCulloch for many conversations which have greatly influenced my views on this subject. I am also grateful to the participants in the discussion at the Royal Institute of Philosophy meeting in February 1997, and to Victor Caston, Katalin Farkas, Marcus Giaquinto, Paul Horwich, Michael Martin, Gregory McCulloch, Paul Noordhof and Scott Sturgeon for comments on earlier versions of the paper.
} 